\title{
The Many Faces of Redundancy in DNA Replication Control
}

\author{
J.F.X. DIFFLEY \\ Cancer Research UK London Research Institute, Clare Hall Laboratories, South Mimms, \\ Hertfordshire EN6 3LD, United Kingdom \\ Correspondence:John.Diffley@cancer.org.uk
}

\begin{abstract}
The large genomes of eukaryotic cells are replicated from multiple replication origins during $\mathrm{S}$ phase of the cell cycle. These origins are not activated synchronously at the beginning of S phase but, instead, fire throughout $\mathrm{S}$ phase according to a predetermined, cell-type-specific program. Ensuring that each origin is efficiently activated once and only once during each S phase is crucial for maintaining the integrity of the genome. This is achieved by a two-step mechanism. The first step, licensing, involves the loading of the Mcm2-7 proteins into pre-replicative complexes (pre-RCs) at origins by ORC, Cdc6, and Cdt1. Pre-RCs can only assemble at origins during $\mathrm{G}_{1}$ phase, when cyclin-dependent kinase (CDK) activity is low because CDKs inhibit each pre-RC component individually. CDKs trigger initiation by phosphorylating two essential proteins, Sld2 and Sld3. A second protein kinase, $\mathrm{Cdc} 7$, along with its regulatory subunit, Dbf4, is also required for initiation. In response to DNA damage, origin firing is inhibited by a third protein kinase, Rad53, which phosphorylates and inhibits Sld3 and Dbf4. In this chapter, I describe these regulatory mechanisms in detail and explore the role of redundancy in the regulation of DNA replication, focusing on the budding yeast, Saccharomyces cerevisiae.
\end{abstract}

In bacteria, relatively small genomes are generally contained on single, often circular DNA molecules and are replicated from single, usually well-defined replication origins (Mott and Berger 2007; Zakrzewska-Czerwinska et al. 2007). There are exceptions to this: the Vibrio cholerae genome is split between two circular chromosomes (Heidelberg et al. 2000), for example, and chromosomes in the genus Borrelia are linear, rather than circular (Chaconas and Kobryn 2010). Although DNA replication is tightly regulated and coupled to cell growth in these organisms, an inappropriate reinitiation event may not be catastrophic because completion of replication from this extra initiation will result in rapid production of a complete extra copy of the genome without any imbalance in genetic information.

The situation is quite different in eukaryotes, where multiple chromosomes are the norm and replication initiates from many origins on each chromosome (Diffley 2004; Arias and Walter 2007; Sclafani and Holzen 2007; Remus and Diffley 2009). Inappropriate reinitiation from a single origin will, at best, lead to an extra copy of one chromosome, causing an imbalance in gene dosage. This best-case scenario is, however, very unlikely: It would take an unimpeded pair of bidirectional replication forks $>6 \mathrm{~d}$ to fully replicate an average-sized $\left(6.5 \times 10^{7} \mathrm{bp}\right)$ human chromosome. The more likely outcome of an unscheduled reinitiation event is some form of replication fork breakdown leading to either cell death or genetic rearrangements (Green et al. 2010).

To ensure exactly one round of DNA replication per cell cycle, eukaryotes use a two-step system to control initiation (Fig. 1) (Remus and Diffley 2009). In the first step, known as licensing, the replicative helicase is loaded at origins into pre-replicative complexes (pre-RCs). The replicative helicase is composed of six related proteins
(Mcm2-7), loaded into head-to-head double hexamers around double-stranded DNA (Remus et al. 2009). Assembly of the pre-RC requires a set of loading factors including the origin recognition complex (ORC), Cdc6, and Cdt1. Importantly, in this configuration, the helicase is inactive and can remain at origins for many hours. In the second step, the helicase is activated via the assembly of a transient pre-initiation complex (pre-IC). In this step, additional factors required for helicase activity, $\mathrm{Cdc} 45$ and GINS, are loaded into a "CMG" complex (Gambus et al. 2006; Moyer et al. 2006) by another set of factors, Sld2, 3, 7, and Dpb11 (Araki 2010).

Origin firing is limited to once per cell cycle because these two steps are separated temporally during the cell cycle. The key cell cycle regulators, cyclin-dependent kinases (CDKs) and the anaphase-promoting complex/cyclosome $(\mathrm{APC} / \mathrm{C})$, have crucial, direct roles in this regulation. Licensing can only occur during $G_{1}$ phase, when $\mathrm{CDK}$ levels are low and the $\mathrm{APC} / \mathrm{C}$ is active, whereas helicase activation and origin firing can only occur after $\mathrm{G}_{1}$ phase, when CDKs are activated and the $\mathrm{APC} / \mathrm{C}$ is inactive. Details of how this is executed and the role of redundancy in this process are the subject of this chapter.

\section{REDUNDANCY IN THE REGULATION OF PRE-RC ASSEMBLY}

In budding yeast, relicensing during $\mathrm{S}, \mathrm{G}_{2}$, and $\mathrm{M}$ phases is directly blocked by cyclin-dependent kinases. Inactivation of $\mathrm{CDKs}$ during $\mathrm{G}_{2} / \mathrm{M}$ by overexpressing the CDK inhibitor Sic1 or targeting the catalytic CDK subunit, $\mathrm{Cdc} 28$, for ubiquitin-mediated proteolysis promotes the relicensing of origins. Rereplication does not occur as long as repression of CDK activity is maintained; how- 


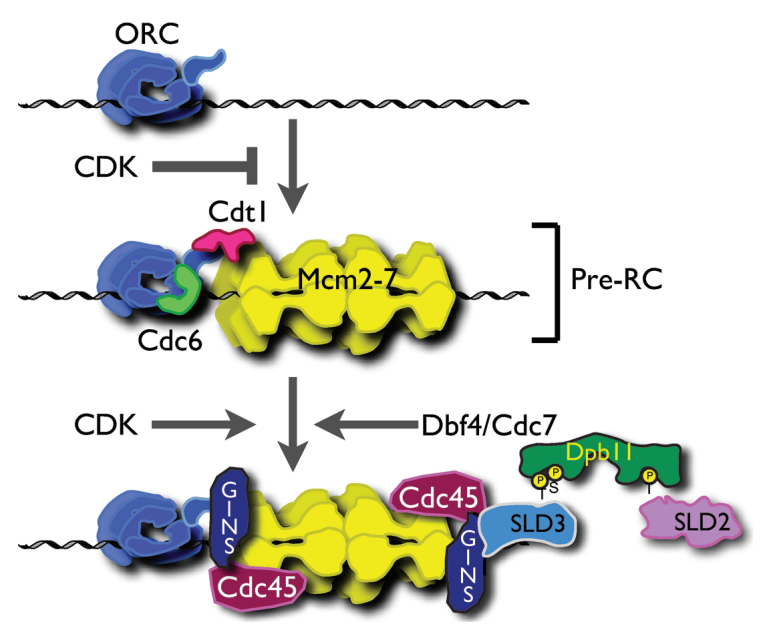

Figure 1. Two steps in the initiation of eukaryotic DNA replication. Depicted are the early steps in eukaryotic DNA replication. Details are described in the text.

ever, if CDK activity is allowed to reaccumulate, a complete additional round of DNA replication occurs with no significant loss of viability, effectively converting cells from haploid to diploid (Dahmann et al. 1995; Noton and Diffley 2000). The additional round of replication induced by transient $\mathrm{CDK}$ inhibition occurs even in the absence of other mitotic regulators including the APC/C (Noton and Diffley 2000). Thus, CDKs have two roles in regulating DNA replication: a positive role in promoting initiation downstream from pre-RC assembly and a negative role in inhibiting rereplication by inhibiting pre-RC assembly. The oscillation of CDK levels during the cell cycle therefore temporally separates the two biochemical reactions required for the initiation of replication, pre-RC assembly, and helicase activation, by defining a period when cells are competent to assemble pre-RCs $\left(\mathrm{G}_{1}\right.$, low CDK) and a period when cells are no longer competent to assemble pre-RCs but can trigger initiation $\left(\mathrm{S}, \mathrm{G}_{2}, \mathrm{M}\right.$, high $\left.\mathrm{CDK}\right)$.

$\mathrm{CDK}$ phosphorylates many pre-RC components directly and, by different mechanisms, prevents them from participating in the licensing reaction (Fig. 2). The Mcm27 complex, along with its associated Cdt1 protein, is excluded from the nucleus during $S, G_{2}$, and $M$ phases by CDK phosphorylation (Hennessy et al. 1990; Labib et al. 1999; Nguyen et al. 2000; Tanaka and Diffley 2002b; Liku et al. 2005). Cde6 is inhibited by CDKs in two different ways during the cell cycle. The $\mathrm{G}_{1}$ cyclins $(\mathrm{Cln})$ phosphorylate Cdc6 on four key residues, generating two distinct binding sites for $\mathrm{Cdc} 4$, the substrate recognition subunit of the SCF ubiquitin ligase (Drury et al. 1997; Elsasser et al. 1999; Jang et al. 2001; Perkins et al. 2001). Consequently, Cdc6 is very rapidly degraded by the proteasome from the end of $\mathrm{G}_{1}$ phase, through $\mathrm{S}$ phase (Drury et al. 1997, 2000). Cdc6 becomes partially stabilized in mitosis despite the presence of high levels of CDK activity (Drury et al. 2000). This is because the mitotic cyclin, Clb2, binds directly and very tightly to CDK-phosphorylated Cdc6 at sites overlapping one of the $\mathrm{SCF}^{\mathrm{Cdc} 4}$ binding sites (Elsasser et al. 1996; Weinreich et al. 2001; Mimura et al. 2004). When bound to $\mathrm{Clb} 2-\mathrm{Cdc} 28$, phosphorylated Cdc6 is no longer able to support Mcm2-7 loading (Mimura et al. 2004). Two ORC subunits (Orc2 and 6) are CDK substrates (Nguyen et al. 2001), and CDK phosphorylation of these proteins contributes to the block to rereplication (Nguyen et al. 2001; Wilmes et al. 2004). The mechanism by which CDK phosphorylation inhibits ORC has not yet been determined. However, because ORC is present and bound at origins throughout the cell cycle, phosphorylation must not inhibit DNA binding or induce significant proteolysis or cytoplasmic relocalization. It is therefore likely that ORC phosphorylation directly inhibits pre-RC assembly, perhaps by interfering with some key protein interactions. In addition to regulation at the level of preRC posttranslational modification, CDKs also control the transcription of several genes encoding pre-RC components including CDC6 and MCM2-7, which need to be resynthesized at the beginning of each cell cycle (Piatti et al. 1995; Braun and Breeden 2007).

Each of these CDK-dependent "inhibitory pathways" contributes to preventing rereplication; however, no single inhibitory pathway is essential for viability, and loss of single pathways does not induce significant levels of reinitiation (Drury et al. 1997; Labib et al. 1999; Nguyen et al. 2000, 2001; Wilmes et al. 2004). In contrast, loss of two inhibitory pathways leads to small but detectable amounts of rereplication, activation of DNA damage checkpoints, and cell death (Mimura et al. 2004; Wilmes et al. 2004; Archambault et al. 2005; Green and Li 2005). Loss of all three inhibitory pathways results in significant amounts of rereplication in $\mathrm{G}_{2} / \mathrm{M}$-arrested cells (Nguyen et al. 2001). However, unlike the rereplication induced by transient CDK inhibition, rereplication induced by loss of all three downstream inhibitory pathways does not result in complete genome reduplication and is accompanied by cell death. Taken together, these results indicate that phosphorylation of each pre-RC component contributes to preventing rereplication in a genetically redundant manner. Moreover, because deregulation of all three inhibitory pathways does not induce rampant rereplication, it is likely that additional, yet unknown pathways contribute to the block to rereplication.
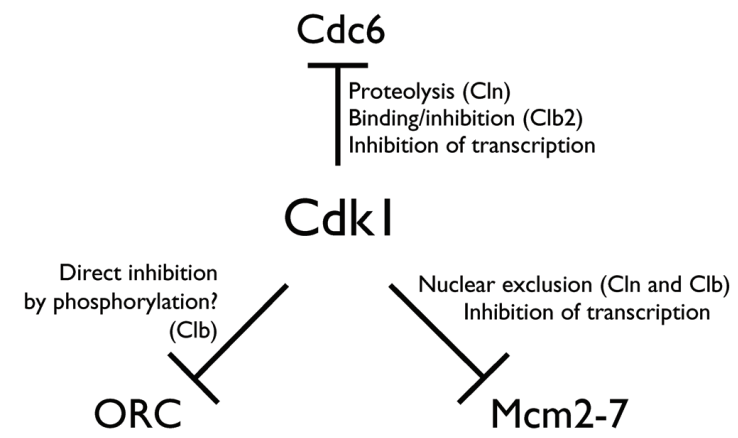

Figure 2. CDK-dependent inhibition in budding yeast. CDKs inhibit licensing outside of $\mathrm{G}_{1}$ phase by multiple pathways depicted. Details are described in the text. 
Why do cells use multiple mechanisms to prevent rereplication? One possibility is that the efficiencies of the individual biochemical mechanisms involved in blocking rereplication such as proteolysis, nuclear export, etc. are simply not sufficient to guarantee a "robust" block to rereplication. To examine this possibility, one needs to have some idea of how efficient the block to rereplication really needs to be. We can begin to approach this with simple probability calculations. The yeast genome is replicated from $\sim 400$ replication origins, and it is important for survival and genome integrity that all 400 origins must be prevented from reinitiating. To reach a $99 \%$ probability of passing through a single $\mathrm{S}$ phase without reinitiating from any origin, the block to rereplication on a per-origin basis must be at least $\sqrt[400]{0.99}=0.99998$. That is, the block to reinitiating replication from any individual origin needs to be $99.998 \%$ efficient, or, put another way, the error rate for reinitiation needs to be $(1-0.99998)=2 \times 10^{-5}$ or less per origin. In fact, the probability of traversing $\mathrm{S}$ phase without any reinitiation is likely to be much higher than $99 \%$, and thus it is likely that the error rate per origin is considerably lower than $10^{-5}$ and may approach the kind of error rates associated with nucleotide misincorporation during replication $\left(10^{-7}-10^{-8}\right)$. It is very unlikely that any single biochemical pathway like phosphorylation, proteolysis, or nuclear export could ever achieve this level of efficiency.

Analogous to nucleotide misincorporation during DNA synthesis, in which multiple mechanisms including proofreading and mismatch repair contribute to lowering the error rate, the multiple pathways preventing rereplication may all contribute to achieving a robust block to rereplication. If each of three "redundant" inhibitory pathways is $99 \%$ efficient on a per-origin basis and reinitiation from an origin will only occur if all three mechanisms fail at that origin, then the probability that an origin will refire is (1 $0.99)^{3}=10^{-6}$; thus, the probability that any individual origin will not refire is $\left(1-10^{-6}\right)=0.999999$. Consequently, the probability that no origin will refire is $(0.999999)^{400}=$ $0.9996(99.96 \%)$. Loss of one of the three mechanisms changes the probability that an origin will refire to (1 $0.99)^{2}=10^{-4}$, the probability that any individual origin will not refire to $\left(1-10^{-4}\right)=0.9999$, and the probability that no origin will refire to $(0.9999)^{400}=0.961(96.1 \%)$. With loss of two of the three mechanisms, the probability that an origin will refire becomes $(1-0.99)=10^{-2}$, the probability that any individual origin will not refire to $\left(1-10^{-2}\right)$ $=0.99$, and the probability that no origin will refire to $(0.99)^{400}=0.018(1.8 \%)$. Interestingly, this seems to reflect the situation in vivo in yeast: Loss of single inhibitory pathways has little or no effect on cell growth, although loss of two inhibitory pathways results in very significant growth defects. For simplicity, the preceding calculations assumed that all three inhibitory pathways have the same efficiency, which is unlikely to be the case in vivo. Indeed, the three pathways in yeast are not equally important in blocking rereplication in yeast. For example, cells lacking ORC and Mcm2-7 regulation are viable (Nguyen et al. 2001), whereas cells lacking ORC and Cdc6 regulation are not (Mimura et al. 2004; Wilmes et al. 2004).
In the calculations above, I considered the efficiencies of individual pathways on a per-origin basis (i.e., 99\% efficiency $=99 \%$ probability an origin will not reinitiate in a single $\mathrm{S}$ phase). How this efficiency compares with the biochemical efficiency of each inhibitory pathway deserves some discussion. ORC acts in cis at origins and is present in cells at roughly one copy per origin; thus, it is likely that the biochemical efficiency of ORC phosphorylation by CDK would equate, roughly, to the efficiency of preventing reinitiation. For example, if $99 \%$ of ORC was phosphorylated, the remaining $1 \%$ of unphosphorylated ORC would be bound at $\sim 1 \%$ of origins, essentially inactivating this inhibitory pathway at those origins. For other pre-RC components, the comparison is less straightforward. From yeast to humans, multiple Mcm2-7 hexamers are apparently loaded per origin, and experiments in Xenopus and humans suggest that Mcm2-7 levels can be greatly reduced without affecting replication rates (Woodward et al. 2006; Ge et al. 2007; Ibarra et al. 2008). Thus, to achieve a $99 \%$ probability of preventing reinitiation per origin, it may be necessary to inhibit (e.g., in yeast by cytoplasmic relocalization) far greater than $99 \%$ of the Mcm2-7 complex. For other proteins, like Cdc6, it is difficult to compare biochemical efficiency of protein inactivation with the probability of reinitiation "per origin" in part because the stoichiometry of Cdc6 in Mcm2-7 loading is unknown and in part because it is unknown whether a single Cdc6 molecule can participate sequentially in Mcm2-7 loading at multiple origins.

It is noteworthy that there are a limited number of ways in which a posttranslational modification can inhibit a protein: targeting it for degradation, directing the binding of an inhibitor, sequestering it from its site of action, or directly preventing it from participating in its biochemical function by preventing some crucial interaction. Interestingly, all of these mechanisms are used in yeast: Cdc6 is targeted for degradation, it is also bound in a phosphorylation-dependent manner to an inhibitor (Clb2), Mcm2-7 is sequestered from the nucleus, and ORC appears to be directly inactivated. Not relying on a single mechanism for pre-RC inactivation may also contribute to the robustness of the block to rereplication.

The probabilistic approach to understanding the contribution of multiple inhibitory pathways to preventing rereplication described above has interesting implications for considering how organisms with larger genomes prevent rereplication. In human somatic cells, for example, somewhere around 50,000 replication origins are used per cell cycle, $\sim 100$ times more than are used in yeast. It turns out that addition of just one additional mechanism for preventing reinitiation is sufficient to achieve the same efficiency as in yeast. If now each of four "redundant" mechanisms is $99 \%$ efficient on a per-origin basis and reinitiation from an origin will only occur if all four mechanisms fail at that origin, then the probability that an origin will refire is $(1-0.99)^{4}=10^{-8}$; thus, the probability that any individual origin will not refire is $\left(1-10^{-8}\right)=$ 0.99999999 . Consequently, the probability that no origin will refire is $(0.99999999)^{50000}=0.9995(99.95 \%)$. Thus, the trend toward larger genomes in evolution did not re- 
quire a complete reinvention of replication control but just required elaboration of the existing approach. In addition to $\mathrm{CDK}$-dependent inhibition of pre-RC assembly, probably via ORC, Cdt1, and Cdc6 phosphorylation (for discussion, see Diffley 2004), metazoans have evolved two additional mechanisms to inhibit licensing outside of $G_{1}$ phase. The first involves geminin, a Cdt1 inhibitor (Wohlschlegel et al. 2000; Tada et al. 2001), which, like cyclins, is an APC/C substrate and consequently absent from $\mathrm{G}_{1}$ cells (McGarry and Kirschner 1998). The second involves the DNA replication-dependent degradation of Cdt1, which requires recruitment of $\mathrm{Cdt} 1$ to chromatin via interaction with PCNA (Zhong et al. 2003; Arias and Walter 2005, 2006; Takeda et al. 2005; Senga et al. 2006). The fact that these additional inhibitory pathways are not directly CDK-dependent may contribute to the robustness of the overall block to rereplication because it may allow the block to be maintained even if CDK oscillations are dampened or otherwise accidentally compromised.

The apparent redundancy of inhibitory pathways has interesting implications for the evolution of regulatory mechanisms. It is striking that different organisms use the same strategies to inhibit pre-RC components outside of $\mathrm{G}_{1}$ phase (SCF-dependent proteolysis, inhibitor binding, nuclear exclusion, etc.); however, the specific details of how individual proteins are regulated varies widely among organisms. For example, in yeast, Cdt1 is inhibited by nuclear exclusion, whereas in mammalian cells, it is inhibited by degradation and inhibitor binding (geminin). Indeed, even within the budding yeasts, there is evidence for evolution of CDK inhibitory mechanisms operating on Cdc6 and Mcm2-7 (Moses et al. 2007; Drury and Diffley 2009). Experiments in yeast suggest that there are two factors that probably contribute to this evolution. The first is the apparent redundancy of the pathways: Individual pathways can be lost without greatly affecting viability/fitness. The second is that there are few restrictions on the types of inhibitory mechanisms that can operate on individual proteins. For example, converting the normally stable yeast Cdt1 protein into an $\mathrm{SCF}^{\mathrm{Cdc} 4}$ substrate or adding a domain that promotes CDK-dependent nuclear exclusion to a stabilized Cdc6 protein can compensate for the loss of other regulatory mechanisms (Drury and Diffley 2009). Thus, inhibitory pathways may have been swapped easily during evolution.

Another reason for why cells use multiple mechanisms to prevent rereplication involves a fundamental design weakness associated with the simple two-step model described above (for discussion, see Diffley 2004). In going from high to low or low to high CDK activity, the cell must traverse intermediate CDK levels. Although this may be exceedingly transient, there is nonetheless a risk that transient levels might allow both origin licensing and origin firing to occur. There are two ways in which the cell may avoid this problem, and it is likely that both are relevant in vivo. One way is to ensure that the block to rereplication is executed at even very low CDK levels, whereas the helicase activation requires considerably higher CDK levels. Thus, any intermediate CDK level would always be either too high to allow licensing or too low to allow origin firing. There is evidence that the inappropriate presence of even low levels of CDK activity during $\mathrm{G}_{1}$ phase can compromise origin licensing, consistent with this idea (Noton and Diffley 2000; Lengronne and Schwob 2002; Tanaka and Diffley 2002a).

A second way to avoid this problem is to use a temporal buffer zone during CDK transitions when neither licensing nor firing can occur. There is evidence that budding yeast uses this approach. For example, $\mathrm{G}_{1}-\mathrm{CDK}$ is activated before S-CDK and cannot, by itself, trigger initiation. Two of the CDK-dependent inhibitory pathways, SCFCdc4-dependent Cdc6 degradation and Mcm2-7 nuclear exclusion, are triggered by $\mathrm{G}_{1}-\mathrm{CDK}$ (Labib et al. 1999; Drury et al. 2000), ensuring that the block to rereplication begins before S-CDK is activated and, therefore, before origin firing can begin. Similarly, at the end of mitosis, two key kinase regulators, Clb5 (required for S-CDK) and Dbf4 (required for Cdc7 activity, described below), are both targeted for degradation by the $\mathrm{Cdc} 20$ form of the $\mathrm{APC} / \mathrm{C}$ at the metaphase-to-anaphase transition (Shirayama et al. 1999; Ferreira et al. 2000). However, the block to relicensing is not lifted until the telophase- $\mathrm{G}_{1}$ transition, when the mitotic cyclin Clb2 is degraded (Diffley et al. 1994). In addition to providing a temporal buffer between the key state changes, this system allows several different CDK and APC/C species to participate in the block to rereplication, which may add additional robustness.

\section{REDUNDANCY IN THE CONTROL OF INITIATION}

In the previous paragraphs, I discussed the role of multiple CDK-dependent inhibitory pathways in the block to rereplication. In this case, phosphorylation of individual CDK substrates acts redundantly in the sense that loss of individual phosphorylations does not significantly compromise viability or the block to rereplication. Redundancy of a different sort has a role in the regulation of initiation downstream from pre-RC assembly. Here, individual phosphorylation sites on several key initiators are each essential for viability, and these phosphorylation events act together to ensure that initiation only occurs when kinase levels are high.

In addition to CDK, activation of the Mcm2-7 replicative helicase and assembly of the pre-IC require a second protein kinase, the Dbf4-dependent kinase (DDK) along with CDK (Labib 2010). There are interesting parallels between CDK and DDK. Like CDK, DDK comprises a catalytic subunit (Cdc7) and a regulatory subunit (Dbf4), required for activity. Moreover, like $\mathrm{CDK}$, the regulatory subunit is targeted for degradation during $G_{1}$ phase by the APC/C. Thus, during $\mathrm{G}_{1}$ phase, neither CDK nor DDK can accumulate.

In recent years, significant progress has been made in understanding how these protein kinases trigger the initiation of DNA replication. Considerable genetic evidence has accumulated indicating that the Mcm2-7 complex is the primary DDK target. The first evidence came from Sclafani and coworkers (Hardy et al. 1997), who identified a mutant (bobl) that could bypass the requirement for both 
Cdc7 and Dbf4. They subsequently showed that bobl is an allele of one of the Mcm2-7 subunits, MCM5. The Mcm2-7 complex was subsequently shown to be an excellent substrate for DDK, but, surprisingly, Mcm5 is not phosphorylated by DDK. It now appears that the Mcm2, 4 , and 6 subunits are the most relevant substrates for DDK in vitro and in vivo (Sheu and Stillman 2006, 2010; Francis et al. 2009; Labib 2010; Randell et al. 2010), and the $m c m 5-b o b 1$ allele in some way phenocopies the effects of Mcm2,4,6 phosphorylation.

Although CDK phosphorylates hundreds of substrates in vivo (Ubersax et al. 2003), the phosphorylation of just two proteins, Sld2 and Sld3, is necessary and sufficient to drive DNA replication in budding yeast (Masumoto et al. 2002; Tanaka et al. 2007; Zegerman and Diffley 2007). Phosphorylation of Sld2 and Sld3 generates binding sites for Dpb11, a protein containing two pairs of BRCT repeats. In both Sld2 and Sld3, CDK phosphorylation involves multiple sites, which may provide a mechanism to ensure that replication does not begin until high levels of CDK are available. CDK phosphorylation of a cluster of 11 sites in Sld2 in some way regulates the accessibility of another site, Thr 84 (Tak et al. 2006). Phosphorylation of Thr 84 is the key event because it generates a binding site for a pair of BRCT repeats (repeats 3 and 4) in the Dpb11 protein (Tak et al. 2006; Zegerman and Diffley 2007). In the case of Sld3, CDK phosphorylation on two sites (Thr600 and Ser622) is required for robust binding to BRCT repeats 1 and 2 of Dpb11 (Zegerman and Diffley 2007). The crystal structure of these BRCT repeats in the human Dpb11 homolog (TopBP1) revealed the presence of two phosphate binding sites - one in each BRCT repeat - providing a potential explanation for the involvement of two phosphorylation sites (Rappas et al. 2011).

Cells harboring the bob1 allele of MCM5 do not require $\mathrm{Cdc} 7$ to initiate DNA replication, yet these cells are viable and do not initiate replication prematurely. Similarly, cells harboring alleles of SLD2 and SLD3 that bypass the requirement for CDK are also viable and do not initiate replication during $\mathrm{G}_{1}$ phase. However, when the CDK bypass alleles of $S L D 2$ and $S L D 3$ are combined with either the bob1 allele, a strain overexpressing Dbf4, or a strain expressing a version of Dbf4 lacking a functional APC/C destruction box, the result is inappropriate initiation during $G_{1}$ phase and lethality (Zegerman and Diffley 2007). Because replication initiates during $\mathrm{G}_{1}$ phase, when $\mathrm{CDK}$ levels are low, there are no blocks to relicensing, and, consequently, this combination of bypass constructs leads to extensive rereplication. Thus, the APC/C prevents premature initiation during $\mathrm{G}_{1}$ phase by preventing the accumulation of both Dbf4 and the S-phase cyclins, revealing another example of redundancy in DNA replication control.

\section{REDUNDANCY IN THE REGULATION OF ORIGIN FIRING BY DNA DAMAGE CHECKPOINTS}

When replication forks from early-firing replication origins encounter lesions in the DNA template or are slowed by depletion of nucleotide precursors, the ensuing activa- tion of the DNA damage checkpoint pathway inhibits the firing of later-firing replication origins (Painter and Young 1980; Larner et al. 1994, 1999; Santocanale and Diffley 1998; Shirahige et al. 1998; Santocanale et al. 1999). This checkpoint network involves a protein kinase cascade that begins with the activation of a phosphatidyl inositol 3' kinase-related kinase (PIKK). There are two critical PIKKs known as ATM (ataxia telangiectasia mutated) and ATR (ATM and Rad3-Related), which, in budding yeast, are known as Tel1 and Mec1, respectively. These PIKKs then activate downstream kinases Chk1 and Chk2, respectively (Chk1 and Rad53 in budding yeast). In budding yeast, activated Rad53 is the kinase directly responsible for inhibiting late origin firing. It has recently been shown that Rad53 inhibits late origin firing by phosphorylating two key initiator proteins, Sld3 and Dbf4 (Lopez-Mosqueda et al. 2010; Zegerman and Diffley 2010). Both proteins are phosphorylated on multiple sites in response to Rad53 activation. Phosphorylation of Sld3 blocks its ability to interact with both Dpb11 and Cdc45 (Zegerman and Diffley 2010). The mechanism by which Dbf4 is inhibited by phosphorylation is not known. Importantly for this discussion, late origin firing by checkpoint activation is still blocked in mutants of either Sld3 or Dbf4 that cannot be phosphorylated by Rad53. Only when unphosphorylatable Dbf4 and Sld3 are combined is the block to late origin firing overridden (Lopez-Mosqueda et al. 2010; Zegerman and Diffley 2010), revealing yet another example of redundancy in DNA replication control.

As shown in Figure 3, regulation of origin firing during the cell cycle and in response to DNA damage operates in a similar manner: In both cases, both the CDK and DDK pathways are inhibited. In the case of the cell cycle, the APC/C (along with help from the CDK inhibitor Sic1) prevents premature initiation during $\mathrm{G}_{1}$ phase by directly down-regulating the two kinases. In the case of DNA damage, DDK is directly regulated by Rad53; however, CDK is not down-regulated. Instead, the CDK pathway is inhibited via the downstream CDK substrate Sld3. This allows CDK to remain active during DNA damage/replication stress. This is crucial in budding yeast because CDK has a critical role in preventing the relicensing of the already-

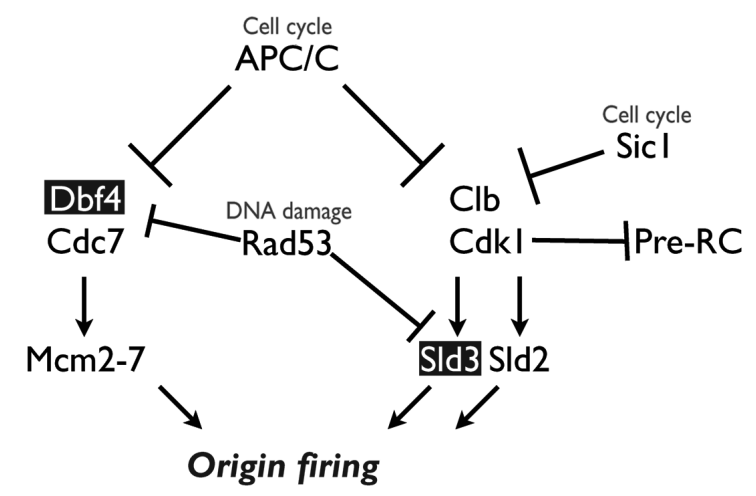

Figure 3. Origin firing in budding yeast is regulated similarly during the cell cycle and in response to DNA damage. Both CDK and DDK pathways are down-regulated during $\mathrm{G}_{1}$ phase by the $\mathrm{APC} / \mathrm{C}$ and after DNA damage by the Rad53 kinase. 
fired early origins (Noton and Diffley 2000). In metazoans, where CDK-independent pathways also contribute to blocking rereplication, there is evidence that DNA damage down-regulates CDK activity by targeting the Cdc25A phosphatase for proteolysis (Falck et al. 2001). It will be interesting to see whether Dbf4 and/or the newly discovered Sld3 homolog Treslin/TICRR (Kumagai et al. 2010; Sanchez-Pulido et al. 2010; Sansam et al. 2010) are also targets of the DNA damage response in human cells.

\section{FINAL THOUGHTS}

We now have a relatively detailed understanding of how DNA replication is regulated both during the cell cycle and in response to DNA damage, particularly in budding yeast. As I have tried to convey in this short chapter, regulation of replication is multilayered, with many examples of redundant control mechanisms. These are probably critical to ensure a very high degree of accuracy in DNA replication. It is interesting to consider that cancer cells, which place a premium on rapid proliferation, often at the expense of accurate genome maintenance, may have compromised some of these control mechanisms. We have previously proposed (Tanaka and Diffley 2002a) that cyclin deregulation, which occurs in most if not all cancers and is probably critical for inducing hyperproliferation, may, as a secondary consequence, induce replication stress by inappropriately inhibiting licensing during $\mathrm{G}_{1}$ phase. It is now known that DNA replication stress occurs very early in carcinogenesis and that subsequent activation of DNA damage responses has a crucial role as a cancer barrier (Bartkova et al. 2005; Gorgoulis et al. 2005). Bypassing this barrier may involve checkpoint down-regulation or may involve up-regulation of licensing factors that might overcome some or all of the CDK-dependent inhibition, in either case, disturbing the normal layers of regulation of replication. It is interesting to consider how this might be exploited to specifically kill cancer cells. I hope a more detailed understanding of how replication is regulated in normal human cells and how it is misregulated in cancer may lead to important new anticancer therapies.

\section{ACKNOWLEDGMENTS}

I am grateful to members of my laboratory for discussions. Work in my laboratory is funded by Cancer Research UK and by grants from the European Research Council (EUKDNAREP 249883) and the Association for International Cancer Research (10-0270).

\section{REFERENCES}

Araki H. 2010. Cyclin-dependent kinase-dependent initiation of chromosomal DNA replication. Curr Opin Cell Biol 22: 766771.

Archambault V, Ikui AE, Drapkin BJ, Cross FR. 2005. Disruption of mechanisms that prevent rereplication triggers a DNA damage response. Mol Cell Biol 25: 6707-6721.

Arias EE, Walter JC. 2005. Replication-dependent destruction of Cdt1 limits DNA replication to a single round per cell cycle in Xenopus egg extracts. Genes Dev 19: 114-126.
Arias EE, Walter JC. 2006. PCNA functions as a molecular platform to trigger Cdt1 destruction and prevent re-replication. Nat Cell Biol 8: 84-90.

Arias EE, Walter JC. 2007. Strength in numbers: Preventing rereplication via multiple mechanisms in eukaryotic cells. Genes Dev 21: 497-518.

Bartkova J, Horejsi Z, Koed K, Kramer A, Tort F, Zieger K, Guldberg P, Sehested M, Nesland JM, Lukas C, et al. 2005. DNA damage response as a candidate anti-cancer barrier in early human tumorigenesis. Nature 434: 864-870.

Braun KA, Breeden LL. 2007. Nascent transcription of MCM2-7 is important for nuclear localization of the minichromosome maintenance complex in $\mathrm{G}_{1}$. Mol Biol Cell 18: 1447-1456.

Chaconas G, Kobryn K. 2010. Structure, function, and evolution of linear replicons in borrelia. Annu Rev Microbiol 64: 185202.

Dahmann C, Diffley JFX, Nasmyth KA. 1995. S-phase-promoting cyclin-dependent kinases prevent re-replication by inhibiting the transition of replication origins to a pre-replicative state. Curr Biol 5: 1257-1269.

Diffley JFX. 2004. Regulation of early events in chromosome replication. Curr Biol 14: R778-R786.

Diffley JFX, Cocker JH, Dowell SJ, Rowley A. 1994. Two steps in the assembly of complexes at yeast replication origins in vivo. Cell 78: 303-316.

Drury LS, Diffley JFX. 2009. Factors affecting the diversity of DNA replication licensing control in eukaryotes. Curr Biol 19: 530-535.

Drury LS, Perkins G, Diffley JFX. 1997. The Cdc4/34/53 pathway targets Cdc6p for proteolysis in budding yeast. $E M B O J \mathbf{1 6}$ : 5966-5976.

Drury LS, Perkins G, Diffley JFX. 2000. The cyclin-dependent kinase Cdc28p regulates distinct modes of Cdc6p proteolysis during the budding yeast cell cycle. Curr Biol 10: 231-240.

Elsasser S, Lou F, Wang B, Campbell JL, Jong A. 1996. Interaction between yeast $\mathrm{Cdc} 6$ protein and B-type cyclin/Cdc28 kinases. Mol Biol Cell 7: 1723-1735.

Elsasser S, Chi Y, Yang P, Campbell JL. 1999. Phosphorylation controls timing of Cdc6p destruction: A biochemical analysis. Mol Biol Cell 10: 3263-3277.

Falck J, Mailand N, Syljuasen RG, Bartek J, Lukas J. 2001. The ATM-Chk2-Cdc25A checkpoint pathway guards against radioresistant DNA synthesis. Nature 410: 842-847.

Ferreira MF, Santocanale C, Drury LS, Diffley JFX. 2000. Dbf4p, an essential S phase-promoting factor, is targeted for degradation by the anaphase-promoting complex. Mol Cell Biol 20: 242-248.

Francis LI, Randell JC, Takara TJ, Uchima L, Bell SP. 2009. Incorporation into the prereplicative complex activates the Mcm27 helicase for Cdc7-Dbf4 phosphorylation. Genes Dev 23: 643-654.

Gambus A, Jones RC, Sanchez-Diaz A, Kanemaki M, van Deursen F, Edmondson RD, Labib K. 2006. GINS maintains association of Cdc45 with MCM in replisome progression complexes at eukaryotic DNA replication forks. Nat Cell Biol 8: 358-366.

Ge XQ, Jackson DA, Blow JJ. 2007. Dormant origins licensed by excess Mcm2-7 are required for human cells to survive replicative stress. Genes Dev 21: 3331-3341.

Gorgoulis VG, Vassiliou LV, Karakaidos P, Zacharatos P, Kotsinas A, Liloglou T, Venere M, Ditullio RA Jr, Kastrinakis NG, Levy $\mathrm{B}$, et al. 2005. Activation of the DNA damage checkpoint and genomic instability in human precancerous lesions. Nature 434: 907-913.

Green BM, Li JJ. 2005. Loss of rereplication control in Saccharomyces cerevisiae results in extensive DNA damage. Mol Biol Cell 16: 421-432.

Green BM, Finn KJ, Li JJ. 2010. Loss of DNA replication control is a potent inducer of gene amplification. Science 329: 943946.

Hardy CF, Dryga O, Seematter S, Pahl PM, Sclafani RA. 1997. $\mathrm{Mcm} 5 / \mathrm{Cdc} 46-\mathrm{bob} 1$ bypasses the requirement for the $\mathrm{S}$ phase activator Cdc7p. Proc Natl Acad Sci 9: 3151-3155.

Heidelberg JF, Eisen JA, Nelson WC, Clayton RA, Gwinn ML, 
Dodson RJ, Haft DH, Hickey EK, Peterson JD, Umayam L, et al. 2000. DNA sequence of both chromosomes of the cholera pathogen Vibrio cholerae. Nature 406: 477-483.

Hennessy KM, Clark CD, Botstein D. 1990. Subcellular localization of yeast CDC46 varies with the cell cycle. Genes Dev 4: 2252-2263.

Ibarra A, Schwob E, Mendez J. 2008. Excess MCM proteins protect human cells from replicative stress by licensing backup origins of replication. Proc Natl Acad Sci 105: 8956-8961.

Jang SW, Elsasser S, Campbell JL, Kim J. 2001. Identification of Cdc6 protein domains involved in interaction with $\mathrm{Mcm} 2$ protein and Cdc4 protein in budding yeast cells. Biochem $J$ 354: 655-661.

Kumagai A, Shevchenko A, Dunphy WG. 2010. Treslin collaborates with TopBP1 in triggering the initiation of DNA replication. Cell 140: 349-359.

Labib K. 2010. How do Cdc7 and cyclin-dependent kinases trigger the initiation of chromosome replication in eukaryotic cells? Genes Dev 24: 1208-1219.

Labib K, Diffley JFX, Kearsey SE. 1999. G -phase and B-type cyclins exclude the DNA-replication factor $\mathrm{Mcm} 4$ from the nucleus. Nat Cell Biol 1: 415-422.

Larner JM, Lee H, Hamlin JL. 1994. Radiation effects on DNA synthesis in a defined chromosomal replicon. Mol Cell Biol 14: 1901-1908.

Larner JM, Lee H, Little RD, Dijkwel PA, Schildkraut CL, Hamlin JL. 1999. Radiation down-regulates replication origin activity throughout the $\mathrm{S}$ phase in mammalian cells. Nucleic Acids Res 27: 803-809.

Lengronne A, Schwob E. 2002. The yeast CDK inhibitor Sic1 prevents genomic instability by promoting replication origin licensing in late $\mathrm{G}_{1}$. Mol Cell 9: 1067-1078.

Liku ME, Nguyen VQ, Rosales AW, Irie K, Li JJ. 2005. CDK phosphorylation of a novel NLS-NES module distributed between two subunits of the Mcm2-7 complex prevents chromosomal rereplication. Mol Biol Cell 16: 5026-5039.

Lopez-Mosqueda J, Maas NL, Jonsson ZO, Defazio-Eli LG, Wohlschlegel J, Toczyski DP. 2010. Damage-induced phosphorylation of Sld3 is important to block late origin firing. Nature 467: 479-483.

Masumoto H, Muramatsu S, Kamimura Y, Araki H. 2002. S-Cdkdependent phosphorylation of Sld2 essential for chromosomal DNA replication in budding yeast. Nature 415: 651-655.

McGarry TJ, Kirschner MW. 1998. Geminin, an inhibitor of DNA replication, is degraded during mitosis. Cell 93: 1043-1053.

Mimura S, Seki T, Tanaka S, Diffley JFX. 2004. Phosphorylationdependent binding of mitotic cyclins to Cdc6 contributes to DNA replication control. Nature 431: 1118-1123.

Moses AM, Liku ME, Li JJ, Durbin R. 2007. Regulatory evolution in proteins by turnover and lineage-specific changes of cyclindependent kinase consensus sites. Proc Natl Acad Sci 104: 17713-17718.

Mott ML, Berger JM. 2007. DNA replication initiation: Mechanisms and regulation in bacteria. Nat Rev Microbiol 5: 343-354.

Moyer SE, Lewis PW, Botchan MR. 2006. Isolation of the Cdc45/Mcm2-7/GINS (CMG) complex, a candidate for the eukaryotic DNA replication fork helicase. Proc Natl Acad Sci 103: 10236-10241.

Nguyen VQ, Co C, Irie K, Li JJ. 2000. Clb/Cdc28 kinases promote nuclear export of the replication initiator proteins Mcm2-7. Curr Biol 10: 195-205.

Nguyen VQ, Co C, Li JJ. 2001. Cyclin-dependent kinases prevent DNA re-replication through multiple mechanisms. Nature 411: 1068-1073.

Noton E, Diffley JFX. 2000. CDK inactivation is the only essential function of the APC/C and the mitotic exit network proteins for origin resetting during mitosis. Mol Cell 5: 85-95.

Painter RB, Young BR. 1980. Radiosensitivity in ataxia-telangiectasia: A new explanation. Proc Natl Acad Sci 77: 7315-7317.

Perkins G, Drury LS, Diffley JFX. 2001. Separate SCF(CDC4) recognition elements target $\mathrm{Cdc} 6$ for proteolysis in $\mathrm{S}$ phase and mitosis. EMBO J 20: 4836-4845.

Piatti S, Lengauer C, Nasmyth K. 1995. Cdc6 is an unstable protein whose de novo synthesis in $G_{1}$ is important for the onset of $S$ phase and for preventing a "reductional" anaphase in the budding yeast Saccharomyces cerevisiae. EMBO J 14: 3788-3799.

Randell JC, Fan A, Chan C, Francis LI, Heller RC, Galani K, Bell SP. 2010. Mec1 is one of multiple kinases that prime the Mcm27 helicase for phosphorylation by Cdc7. Mol Cell 40: 353-363.

Rappas M, Oliver AW, Pearl LH. 2011. Structure and function of the Rad9-binding region of the DNA-damage checkpoint adaptor TopBP1. Nucleic Acids Res 39: 313-324.

Remus D, Diffley JFX. 2009. Eukaryotic DNA replication control: Lock and load, then fire. Curr Opin Cell Biol 21: 771-777.

Remus D, Beuron F, Tolun G, Griffith JD, Morris EP, Diffley JFX. 2009. Concerted loading of Mcm2-7 double hexamers around DNA during DNA replication origin licensing. Cell 139: 719 730.

Sanchez-Pulido L, Diffley JFX, Ponting CP. 2010. Homology explains the functional similarities of Treslin/Ticrr and Sld3. Curr Biol 20: R509-R510.

Sansam CL, Cruz NM, Danielian PS, Amsterdam A, Lau ML, Hopkins N, Lees JA. 2010. A vertebrate gene, ticrr, is an essential checkpoint and replication regulator. Genes Dev 24: 183-194.

Santocanale C, Diffley JFX. 1998. A Mec1- and Rad53-dependent checkpoint controls late-firing origins of DNA replication. $\mathrm{Na}$ ture 395: 615-618.

Santocanale C, Sharma K, Diffley JFX. 1999. Activation of dormant origins of DNA replication in budding yeast. Genes Dev 13: $2360-2364$.

Sclafani RA, Holzen TM. 2007. Cell cycle regulation of DNA replication. Annu Rev Genet 41: 237-280.

Senga T, Sivaprasad U, Zhu W, Park JH, Arias EE, Walter JC, Dutta A. 2006. PCNA is a cofactor for Cdt1 degradation by CUL4/DDB1-mediated N-terminal ubiquitination. J Biol Chem 281: 6246-6252.

Sheu YJ, Stillman B. 2006. Cdc7-Dbf4 phosphorylates MCM proteins via a docking site-mediated mechanism to promote $S$ phase progression. Mol Cell 24: 101-113.

Sheu YJ, Stillman B. 2010. The Dbf4-Cdc7 kinase promotes S phase by alleviating an inhibitory activity in $\mathrm{Mcm} 4$. Nature 463: 113-117.

Shirahige K, Hori Y, Shiraishi K, Yamashita M, Takahashi K, Obuse C, Tsurimoto T, Yoshikawa H. 1998. Regulation of DNAreplication origins during cell-cycle progression. Nature 395: 618-621.

Shirayama M, Toth A, Galova M, Nasmyth K. 1999. APC(Cdc20) promotes exit from mitosis by destroying the anaphase inhibitor Pds1 and cyclin Clb5. Nature 402: 203-207.

Tada S, Li A, Maiorano D, Mechali M, Blow JJ. 2001. Repression of origin assembly in metaphase depends on inhibition of RLFB/Cdt1 by geminin. Nat Cell Biol 3: 107-113.

Tak YS, Tanaka Y, Endo S, Kamimura Y, Araki H. 2006. A CDKcatalysed regulatory phosphorylation for formation of the DNA replication complex Sld2-Dpb11. EMBO J 25: 1987-1996.

Takeda DY, Parvin JD, Dutta A. 2005. Degradation of Cdt1 during $\mathrm{S}$ phase is Skp2-independent and is required for efficient progression of mammalian cells through $\mathrm{S}$ phase. J Biol Chem 280: 23416-23423.

Tanaka S, Diffley JFX. 2002a. Deregulated G -cyclin expression induces genomic instability by preventing efficient pre-RC formation. Genes Dev 16: 2639-2649.

Tanaka S, Diffley JFX. 2002b. Interdependent nuclear accumulation of budding yeast Cdt1 and Mcm2-7 during $\mathrm{G}_{1}$ phase. Nat Cell Biol 4: 198-207.

Tanaka S, Umemori T, Hirai K, Muramatsu S, Kamimura Y, Araki H. 2007. CDK-dependent phosphorylation of Sld 2 and Sld3 initiates DNA replication in budding yeast. Nature 445: 328-332.

Ubersax JA, Woodbury EL, Quang PN, Paraz M, Blethrow JD, Shah K, Shokat KM, Morgan DO. 2003. Targets of the cyclindependent kinase Cdk1. Nature 425: 859-864.

Weinreich M, Liang C, Chen HH, Stillman B. 2001. Binding of cyclin-dependent kinases to ORC and Cdc6p regulates the chromosome replication cycle. Proc Natl Acad Sci 98: 11211-11217.

Wilmes GM, Archambault V, Austin RJ, Jacobson MD, Bell SP, Cross FR. 2004. Interaction of the S-phase cyclin Clb5 with an 
"RXL" docking sequence in the initiator protein Orc6 provides an origin-localized replication control switch. Genes Dev 18: 981-991.

Wohlschlegel JA, Dwyer BT, Dhar SK, Cvetic C, Walter JC, Dutta A. 2000. Inhibition of eukaryotic DNA replication by geminin binding to Cdt1. Science 290: 2309-2312.

Woodward AM, Gohler T, Luciani MG, Oehlmann M, Ge X, Gartner A, Jackson DA, Blow JJ. 2006. Excess Mcm2-7 license dormant origins of replication that can be used under conditions of replicative stress. J Cell Biol 173: 673-683.

Zakrzewska-Czerwinska J, Jakimowicz D, Zawilak-Pawlik A,
Messer W. 2007. Regulation of the initiation of chromosomal replication in bacteria. FEMS Microbiol Rev 31: 378-387.

Zegerman P, Diffley JFX. 2007. Phosphorylation of Sld2 and Sld3 by cyclin-dependent kinases promotes DNA replication in budding yeast. Nature 445: 281-285.

Zegerman P, Diffley JF. 2010. Checkpoint-dependent inhibition of DNA replication initiation by Sld3 and Dbf4 phosphorylation. Nature 467: 474-478.

Zhong W, Feng H, Santiago FE, Kipreos ET. 2003. CUL-4 ubiquitin ligase maintains genome stability by restraining DNAreplication licensing. Nature 423: 885-889. 


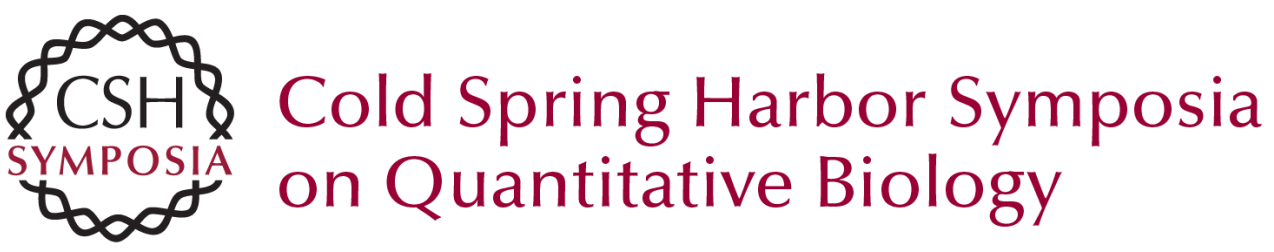

\title{
The Many Faces of Redundancy in DNA Replication Control
}

\author{
J.F.X. Diffley
}

Cold Spring Harb Symp Quant Biol 2010 75: 135-142 originally published online April 18, 2011 Access the most recent version at doi:10.1101/sqb.2010.75.062

References This article cites 78 articles, 30 of which can be accessed free at: http://symposium.cshlp.org/content/75/135.full.html\#ref-list-1

\section{License}

Email Alerting Receive free email alerts when new articles cite this article - sign up in Service the box at the top right corner of the article or click here. 